\title{
The Physiology of Somatostatin in the Rabbit Retina
}

\author{
Robert A. Zalutsky and Robert F. Miller \\ Washington University School of Medicine, Department of Ophthalmology, St. Louis, Missouri 63110
}

The neuropeptide somatostatin (SS) has been localized to neurons of the rabbit retina by immunochemical and biochemical methods (Sagar et al., 1982, 1986; Marshak and Yamada 1984). We examined the effects of bath-applied SS on neurons of the rabbit retina, using intra- and extracellular electrophysiological techniques in an in vitro retina eyecup preparation.

All commonly encountered ganglion cell receptive field types were affected by SS, and the effects were of 3 kinds: The first was a general excitation, occurring with a threshold concentration of about $100 \mathrm{~nm}$; the onset of the excitation was too slow (seconds) for SS to participate in any rapid light-evoked responses. The second SS effect was an increase in the "signal-to-noise ratio," defined here as the ratio of light-evoked to spontaneous spiking, which resulted from a decrease in spontaneous activity and, usually, a concomitant increase in light-evoked spiking. The third effect was a shift in center-surround balance towards a more dominant center. The signal-to-noise and center-surround effects were evident at concentrations as low as $0.5 \mathrm{~nm}$; both were slow onset (tens of seconds) and long lasting (tens of minutes).

SS acted at multiple levels within the retinal circuitry to produce the observed changes in ganglion cell output. These effects included direct actions on ganglion and amacrine cells, and a decrease in the efflclency with which horizontal cells could drive the retinal network. At least part of these SS actions on third-order neurons resulted from a decrease in conductance to ions with an equilibrium potential more positive than dark membrane potential. The degradationresistant SS agonist SMS201-995 had effects qualitatively and quantitatively similar to those of SS, suggesting that SS may be degraded slowly enough to act at a distance from its sites of release.

While no adequate SS antagonist is available, the greater sensitivity to exogenous SS, in retinas depleted of their SS content (with cysteamine), suggests a role for endogenous SS. The potency of SS also reinforces this view.

The results of this study suggest that SS may be a neu-

Received Jan. 23, 1989; revised July 17, 1989; accepted July 18, 1989.

This research was supported by NEI grants EY03014 and EY07057.

Correspondence should be addressed to Robert A. Zalutsky at his present address: Department of Pharmacology, S-1210, University of California at San Francisco Medical School, San Francisco, CA 94143.

Reprint requests should be addressed to Robert F. Miller at his present address Department of Physiology, University of Minnesota, 6-255 Millard Hall, Minneapolis, MN 55455

Copyright (C) 1990 Society for Neuroscience $0270-6474 / 90 / 100383-11 \$ 02.00 / 0$ romodulator in the rabbit retina, producing long-lasting changes in the "signal-to-noise" discharge pattern and center-surround balance of ganglion cells.

The neuropeptide somatostatin (SS) has been localized to the rabbit retina by immunochemical (Sagar et al., 1982, 1986) and chromatographic (Sagar et al., 1982; Marshak and Yamada, 1984) techniques. At least some of the SS immunoreactivity is present in a subclass of amacrine cells (Sagar et al., 1986). A wide range of functions have been attributed to this peptide in the nervous system, which include not only neurotransmitterlike roles (reviewed in Epelbaum, 1986; Delfs and Dichter, 1985), but also hormonal functions, such as in the regulation of glucose metabolism (Robbins, 1983) and a role in neuronal survival (Grimm-Jørgenson, 1987). Here, we demonstrate that low doses of bath-applied SS act at multiple levels of the retinal network; these actions converge to produce long-lasting changes in the receptive field organization of ganglion cells. This suggests that SS may be a ncuromodulator in the rabbit retina.

Some of these results have been briefly reported (Zalutsky and Miller, 1985, 1987).

\section{Materials and Methods}

Experiments were performed using an in vitro retina-eyecup preparation of the rabbit, bath application of peptides, and intracellular and wholecell recording techniques, together with single-unit extracellular electrophysiological studies. This preparation was specifically developed to maintain the health of the retina with appropriately low perfusion rates to allow bath application of drugs, while maintaining intra- and extracellular recordings; the details and validation of an earlier version of this method have been reported (Miller et al., 1986).

Pigmented rabbits $(2-5 \mathrm{~kg})$ were generally anesthetized with urethane ( $25 \%$, i.p.) or the combination of zylazine (Rompin) and ketamine (i.m.). Two different anesthetic protocols were used because peptides, in general, and SS, in particular (e.g., VanItallic and Fernstrom, 1982), are differently affected by different anesthetic procedures. No differences were noted between the 2 procedures or between eyes from animals which had been anesthetized for short periods $(10 \mathrm{~min})$ or much longer periods $(>3 \mathrm{hr})$. When the animals were generally anesthetized, the tissue around the orbit was infused with local anesthetic (lidocaine) and the eye was enucleated.

The anterior parts of the eye and the vitreous were dissected away, after which the eyecup (retina with attached pigment epithelium and sclera) was everted over a Teflon dome. A second Teflon piece was secured on top of the dome, forming a superfusion chamber over the retina. The volume of the chamber was approximately $0.1 \mathrm{ml}$; the rate of flow (gravity fed) was 3-4 ml/min; and the exchange was uniform and reliable. Prior to reaching the chamber, the perfusate was heated to $35-37^{\circ} \mathrm{C}$ with a small, in-line heating coil; temperature was continuously monitored by a thermocouple probe in the retinal bathing medium.

The perfusate consisted of a control solution (below) or the same solution to which peptides or other drugs had been added at defined concentrations. The various solutions were contained in reservoirs which could be separately directed to the retina by valves. The control perfusate consisted of salts [in mM: $\mathrm{NaCl}, 120 ; \mathrm{KCl}, 3.1 ; \mathrm{KH}_{2} \mathrm{PO}_{4}, 0.5 ; \mathrm{NaHCO}_{3}$, 

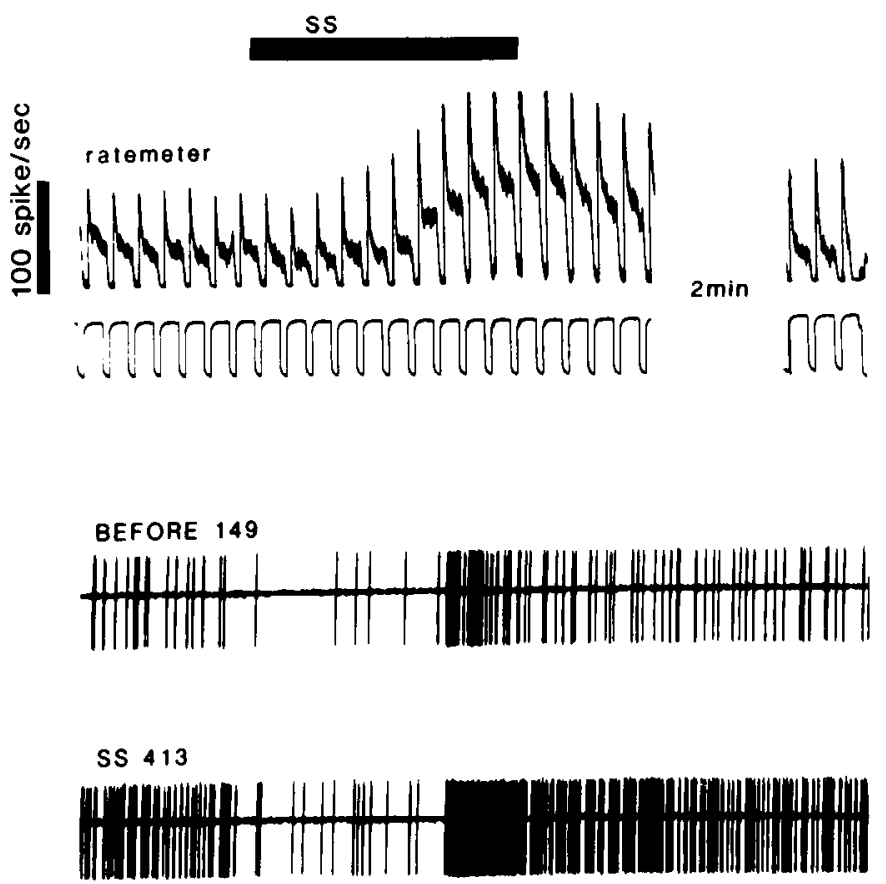

Figure 1. Somatostatin at higher concentrations excited most ganglion cells (see Table 1). Top trace, ratemeter records; two lower records, individual light responses before and after application of $400 \mathrm{nM}$ SS to an Off ganglion cell. The numbers indicate spikes per stimulus cycle before (average) and after (peak) SS application. The large spot stimulus was $2 \mathrm{sec}$, and its presentation is indicated in the bottom trace of cach figure section.

$\left.23 ; \mathrm{MgSO}_{4} \cdot 7 \mathrm{H}_{2} \mathrm{O}, 1.2 ; \mathrm{CaCl}_{2} \cdot 2 \mathrm{H}_{2} \mathrm{O}, 1.15\right]$ plus organics, including amino acids, vitamins, and cofactors exactly as described by Ames and Nesbett (1981). All reservoirs were bubbled continuously with $95 \%$ oxygen $/ 5 \%$ carbon dioxide, producing a pH of 7.4 at $37^{\circ} \mathrm{C}$.

Peptides were obtained from Bachem or Peninsula. They were dissolved in concentrated aliquots, stored frozen at $-70^{\circ} \mathrm{C}$, and thawed and diluted as needed. Non-Teflon parts of the perfusion system were coated using Pierce Surfacil ( $10 \% \mathrm{wt} / \mathrm{vol}$ in carbon tetrachloride) to minimize peptide adhesion. The stability of peptides in the reservoirs and their passage through the perfusion system were checked using HPLC as described previously (Zalutsky and Miller, 1986). Other drugs (GABA, glutamate, glycine, kainate, and carbachol) were routinely used for comparison; all were obtained from Sigma.

Levick-type (Levick, 1972) tungsten-in-glass electrodes and conventional amplification were used for single-unit extracellular recordings. Raw spike data or continuous ratemeter records are presented rather than averaged peristimulus time histograms. Ratemeter records better represent the time course of drug action (which is important here) and allow shorter drug applications when compared with histogram averaging techniques.

Ganglion cell types were discriminated using spots, annuli, diffuse lights, and slits of various velocities and orientations, projected from a conventional, dual-beam light bench with a tungsten-halogen source. A duplicate (but enlarged) projection of the image falling on the retina facilitated cell identification and mapping of receptive fields. Cells were classified according to previously described criteria (especially Caldwell and Daw, 1978, and Vaney et al., 1981).

Intracellular recordings used short taper pipettes of 100-200 M $\Omega$ resistances, filled with $1.5 \mathrm{M}$ potassium methylsulfate, and conventional amplification and current-injection methods. Recordings were monitored by an oscilloscope and stored on chart recorder and FM tape.

Whole-cell recordings used the same rabbit eyecup preparation. The whole-cell recording method described by Coleman and Miller (1986) for amphibian retinas was used, with modifications to accommodate a mammalian retina. After the retina was perfused for about 20 min (to recover from surgery), the perfusion was stopped and approximately 25 $\mu \mathrm{L}$ of an enzyme solution was placed over the retina. The solution was designed to remove the thin layer of vitreous which remained after mechanical dissection because this material prevents sealing of wholecell electrodes to cells. The solution contained trypsin-free CLSPA collagenase (Worthington) and hyaluronidase (Sigma) at about $0.25-1 \mathrm{mg} /$ $\mathrm{ml}$, each dissolved in normal perfusate. During the 3-6 min incubation a cap was placed over the retina, and moist $95 \%$ oxygen $/ 5 \%$ carbon dioxide was supplied. The enzyme solution and as much vitreous as possible were then removed with a tissue (Kimwipe), and the normal perfusion was resumed. Whole-cell electrodes of 8-15 M $\Omega$ were filled with the following (in mM): $\mathrm{KCH}_{3} \mathrm{SO}_{4}, 120 ; \mathrm{CaCl}_{2}, 1 ; \mathrm{MgCl}_{2}, 3 ; \mathrm{HEPES}$, 5; EGTA, 11; glucose, 2; Na-ATP, 2; glutathione, 1; pH 7.2 with $\mathrm{KOH}$. Their signal was monitored using a Dagan 8900 whole-cell amplifier, and current commands were controlled by Axon instruments Pclamp software. The signal was also fed into an audio monitor so the spiking of ganglion cells (extracellularly recorded) could serve as a guide to their location.

The transretinal electroretinogram (ERG) was recorded between $\mathrm{Ag}$ / $\mathrm{AgCl}$ contacts at the sclera and in the perfusate above the retina. The ERG was monitored during all experiments to determine the health of the preparation.

\section{Results}

\section{General SS actions on ganglion cells}

We studied the effects of SS on 147 ganglion cells using extracellular recording techniques. The net effects of SS on these neurons included 3 actions: (1) a general excitation, (2) an increase in the ratio of light-evoked to spontaneous spiking (signalto-noise ratio), and (3) a change in center-surround balance.

The first temporal effect of bath-applied SS on ganglion cells was an enhancement of both light-evoked and spontaneous spiking. The excitation was usually strong enough to produce a several-fold increase in the rate of firing, but a depolarizing block of spiking never occurred, as it commonly does with an appropriate level of more conventional excitatory transmitters (excitatory amino acid and cholinergic agonists) in this preparation. Furthermore, light-evoked inhibitions persisted during SSevoked excitation. Figure 1 shows both continuous ratemeter (upper recording) and individual light response records (lower 2 recordings) of the excitatory effect of SS on an Off ganglion cell. The excitations were the most rapid of the SS effects, but they wcre always a few seconds slower in onset than the effects of excitatory amino acid analogs, cholinergic agonists, or substance $P$ applied to the same cells.

The second effect of SS on ganglion cells was a strong increase in the ratio of light-evoked to spontaneous activity, or, for simplicity, an increase in the "signal-to-noise" ratio. This resulted from a suppression of spontaneous activity, with either no change or (usually) an absolute increase in light-evoked spiking. The minimum SS concentrations producing such effects were about $0.5 \mathrm{~nm}$. Figure 2 illustrates the effect of just $1 \mathrm{~nm}$ SS applied to an On cell. The numbers above the spike records indicate that the spontaneous activity decreased by $70 \%$, while the On response increased by $50 \%$. At slightly higher concentrations, spontaneous activity is often completely suppressed, while light responses increase further (as shown in rig. 6 below). For Off cells, the Off response was selectively increased; and for direction-selective cells, only the preferred direction spiking increased (Fig. 11, below). Thus, the increase in light-evoked spiking of ganglion cells was always an enhancement of the dominant light-evoked discharge of the cell.

The third effect of SS on ganglion cells was a shift in centersurround balance toward a more dominant center. SS affected both the suppressive surround influence, that is, the surround 


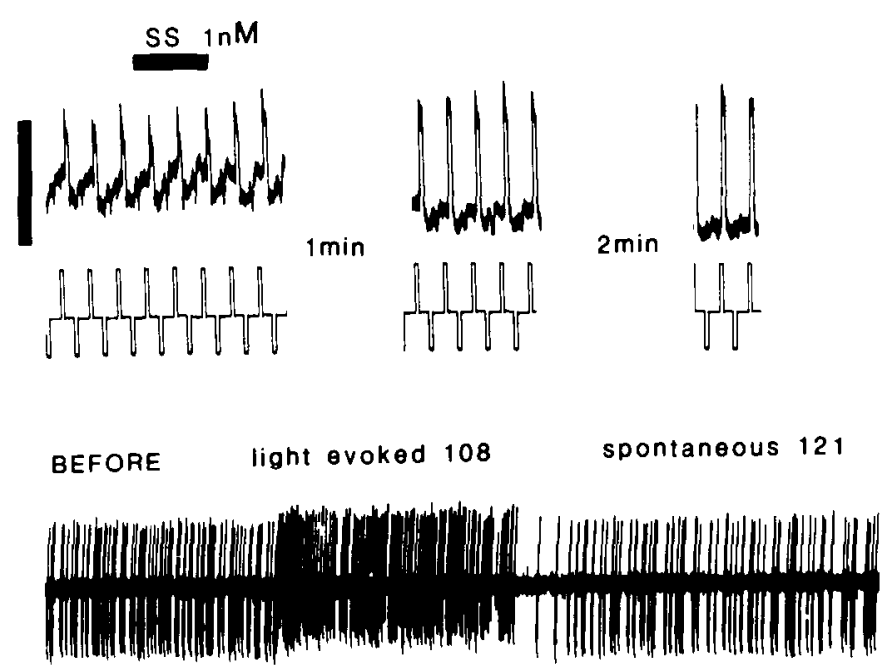

AFTER SS

158

37

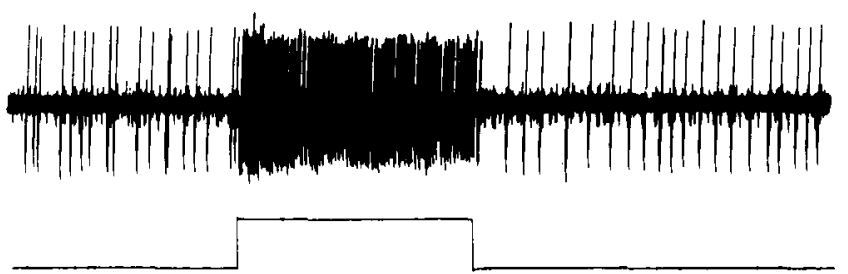

Figure 2. Somatostatin, even at very low concentrations, increased the ratio of light-evoked to spontaneous spiking in ganglion cells. Top traces, ratemeter records; two lower traces, spike data before and after the application of $1 \mathrm{~nm}$ SS. The numbers indicate average numbers of lightevoked and spontaneous spikes per light cycle. Note that the lightevoked spiking increased, while the spontaneous spiking decreased following SS. The light stimulus was 1 sec.

suppression of the center response, and the excitatory surround input, that is, the On responses produced by annulus presentation to Off cells and Off annulus responses seen in On cells. Figure $3 \mathrm{~A}$ shows an Off cell responding to a spot and an annulus before and at 3 different intervals after the introduction of SS. Before the application of SS, the annulus evoked primarily an On (surround) excitation with a small Off (center) response. After SS, the On (surround) excitation from the annulus disappeared and the Off (center) responses to both stimuli increased. The On response returned about $30 \mathrm{~min}$ after the SS application had been terminated. This demonstrates that SS reduced the excitatory surround influence.

Figure $3 B$ shows another experimental paradigm which revealed a change in the inhibitory surround following SS. The graph shows the number of On (center) spikes per stimulus presentation provoked by different diameter spots presented to an On ganglion cell. Before SS, the response increased as the spot size was increased to fill the center of the receptive field, then progressively decreased as the spots were enlarged to encroach upon the surround. $\Lambda$ fter $S S$, the suppressive effect of the larger spots was clearly reduced. (All responses were $<50 \%$ of the maximal light-evoked responses of the cell, so a ceiling or saturation effect was not involved.)

One consequence of the change in center-surround balance by $\mathrm{SS}$ was that the area over which a center response could be elicited was enlarged. Figure $3 C$ clearly illustrates this result of
A.
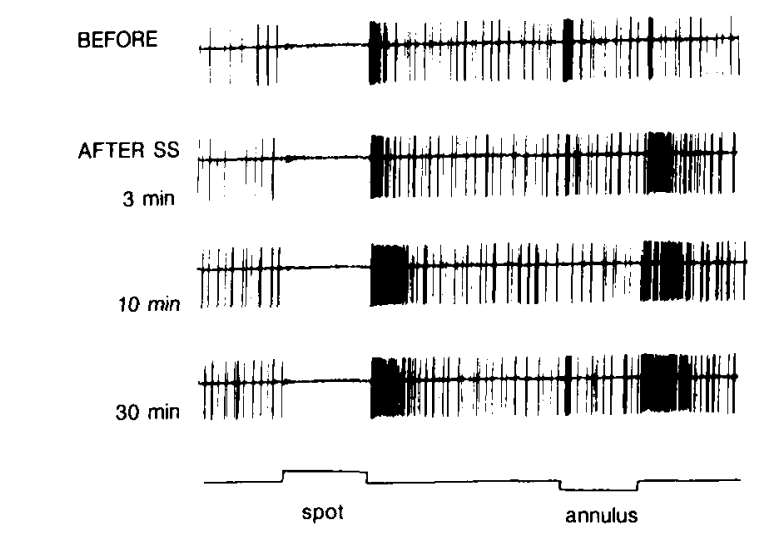

B.

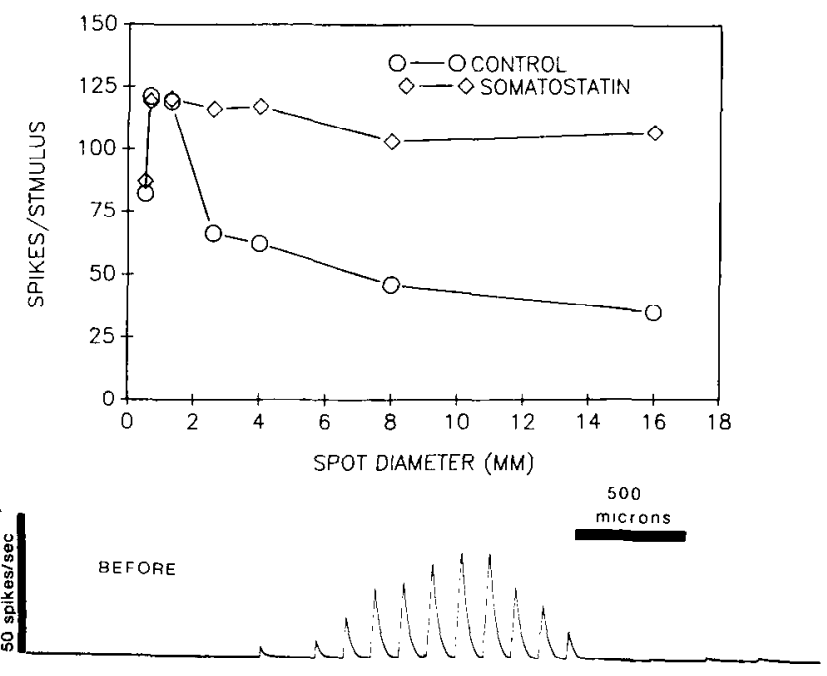

AF TER SS

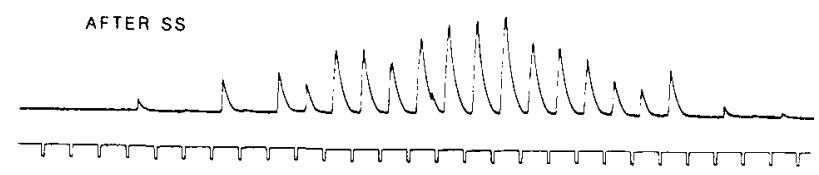

Figure 3. A, Somatostatin shifted the center-surround balance of ganglion cells toward a more dominant center. The spot and annulus responses of an Off cell are shown, before and at the indicated intervals after application of $10 \mathrm{~nm} \mathrm{SS}$ for $1 \mathrm{~min}$. Note that before SS, the annulus produced primarily on On (surround) excitation with only a small Off (center) response. After SS, the Off (center) responses to both the spot and the annulus increased, while the On (surround) excitation from the annulus was eliminated. The On response to the annulus began to recover after about $30 \mathrm{~min}$. $B$. Graph illustrating the reduction of surround suppression in an On cell following SS. Before SS (lower curve. open circles), the number of On (center) spikes per stimulus presentation first increased as the spot size was increased to fill the center of the receptive field, then progressively decreased as the spot was further enlarged to encroach upon the surround. After SS (upper curve, open squares), the surround suppression from larger spots was much reduced. $C$. The centcr-surround shifts produced by SS increased the area over which a center response could be elicited, as indicated by these ratemeter records from an Off cell. The records were produced by moving a $100-\mu \mathrm{M}$-wide flashing slit of light across the retina. All responses elicited by the slit were Off (center) responses in this example. The calibration bars indicate $500 \mu \mathrm{M}$ distance traveled by the moving slit.

exogenous SS, by showing the ratemeter records produced by moving a flashing slit stepwise across the retina before and after SS application. All responses to the narrow (100 $\mu \mathrm{M})$ slit from this Off cell were off (center) responses. The increase in effective center area was apparent, even though the response to the op- 


\begin{tabular}{lccc}
\hline Table 1. Somatostatin effects on ganglion cells & \\
& & & \\
& General & Light-evoked & \\
\cline { 3 - 3 } Concentration & excitation & Spontaneous & $\begin{array}{c}\text { Center- } \\
\text { surround }\end{array}$ \\
\hline \multirow{2}{*}{$<1 \mu \mathrm{M}$} & $9 / 16$ & $10 / 15$ & $6 / 10$ \\
& $(60 \%)$ & $(66 \%)$ & $(60 \%)$ \\
$<500 \mathrm{nM}$ & $11 / 19$ & $14 / 19$ & $9 / 12$ \\
& $(58 \%)$ & $(74 \%)$ & $(75 \%)$ \\
$<250 \mathrm{nM}$ & $13 / 28$ & $20 / 28$ & $17 / 25$ \\
& $(46 \%)$ & $(71 \%)$ & $(68 \%)$ \\
$<125 \mathrm{nM}$ & $4 / 19$ & $15 / 19$ & $11 / 15$ \\
& $(21 \%)$ & $(79 \%)$ & $(73 \%)$ \\
$<10 \mathrm{nM}$ & $0 / 17$ & $9 / 17$ & $10 / 17$ \\
& $(0 \%)$ & $(53 \%)$ & $(58 \%)$
\end{tabular}

Somatostatin had 3 effects on extracellularly recorded ganglion cells: (1) a general excitation, (2) an increase in the ratio of light-evoked to spontaneous spiking, and (3) a shift in center-surround balance toward a more dominant center. The table shows the numbers of cells exhibiting each effect/total numbers of cells at different concentrations of SS; percentages are given in parentheses. The tabulation is not cumulative; e.g., $<500 \mu \mathrm{M}$ indicates $<500 \mu \mathrm{M}$ but $>250 \mu \mathrm{M}$, the next category. All cells included in the table were recorded from healthy retinas (by ERG and ganglion cell light response criteria) which had not previously been exposed to SS or other drugs which might confound the interpretation.

timal slit was not increased in this particular example. Again, the maximum light response of the cell to an optimal size spot was much greater than any responses evoked by the slit in this illustration, so that response saturation does not play a role in this phenomenon.

The latency of the signal-to-noise and center-surround changes was tens of seconds after SS was introduced, and the duration of SS action was tens of minutes to sometimes more than an hour following a 20-60 sec SS application. The minimum concentration which produced these effects was about $0.5 \mathrm{~nm}$. The duration of the center-surround alterations induced by SS was generally tens of minutes and in some cases longer than an hour. In general, the less profound the center-surround or signal-tonoise changes, the more quickly they reversed.

Table 1 shows the numbers of cells in our sample which showed the 3 phenomena associated with SS application, including (1) excitation, (2) an increase in signal-to-noise ratio, and (3) alterations in center-surround balance associated with different SS concentrations. Since peptide effects may depend strongly on the health of the preparation and previous exposure to drugs, Table 1 was compiled from 94 cells which were unquestionably free from such influences. That is, no previous drugs had been administered, and the retinas were clearly healthy by both ERG and extracellular single-unit criteria. While the 3 SS effects have been described as separate, most cells showed a combination of such actions.

\section{Ganglion cell subtypes}

SS affected all ganglion cell receptive field types encountered in this study, including On and Off center, sustained and transient brisk cells, large field units, both On and On-Off directionselective cells, and at least the concentric types of sluggish cells. There was considerable variability in the potency of SS among cells (compared with the more consistent actions of conventional transmitters applied to the same cells), but it appears that variability among retinas (as indicated by the ERG, discussed below) rather than variability among receptive field types is the relevant variable.
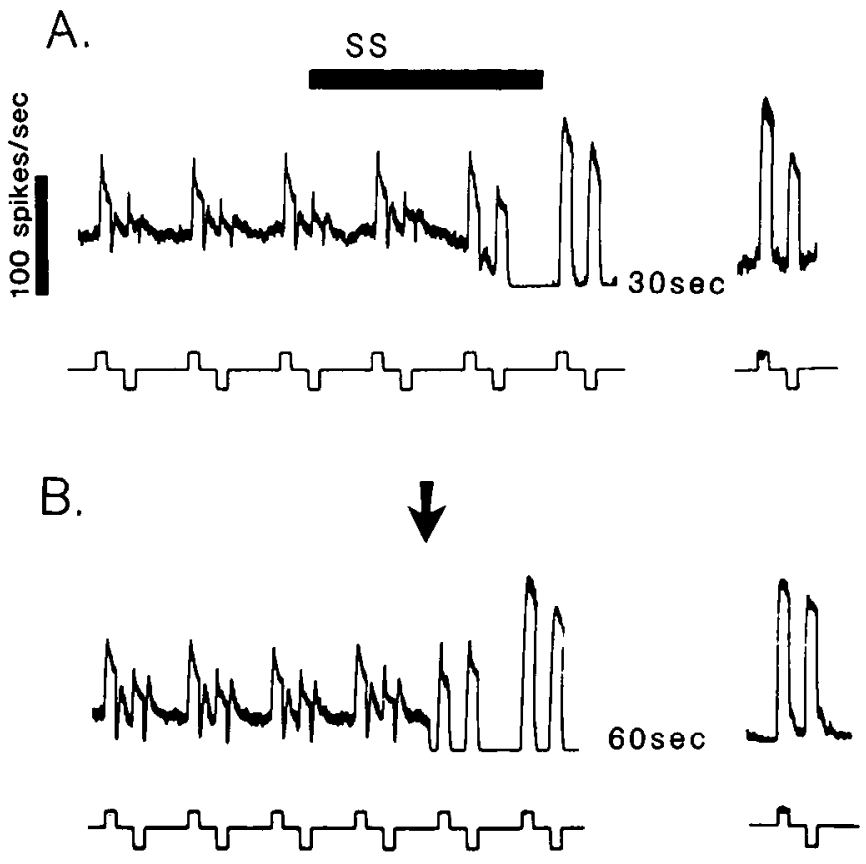

Figure 4. Comparison of the effects of SS and reducing a background light on the discharge pattern of a retinal ganglion cell. The receptive field changes produced by SS can be mimicked by simple changes in light stimuli. Both ratemeter records are from the same sustained On ganglion cell responding to a spot (upward deflection in stimulus trace) and an annulus (downward deflection). $A$, Effect of a SS application. $B$, Effect of extinguishing a background light (at arrow). In both cases, the spontaneous activity decreased, while the center (On) responses to both stimuli increase and the surround (Off) response is eliminated. The SS application (dark bar) was $30 \mathrm{sec}$.

\section{SS actions and retinal location}

Immunohistochemical staining for SS in the rabbit retina (Sagar et al., 1982) shows an absence of SS-immunoreactive cell bodies in the area of the retina superior to the myelinated band. Hence, we examined the effects of SS on cells in different areas of the retina. SS effects were approximately equal in all areas of the retina, including central and peripheral, superior and inferior, and within and outside of the visual streak.

\section{Background lights}

SS was applied to cells with a range of background lights from more than $100 \mathrm{~cd} / \mathrm{m}^{2}$ to less than $0.01 \mathrm{~cd} / \mathrm{m}^{2}$ equivalents in the intact eye. There was no apparent variation in SS effects with adaptational state. However, the changes in receptive field properties (particularly center-surround balance, as in Barlow et al., 1957) with different backgrounds made meaningful comparisons difficult. Indeed, the effects of SS on receptive field properties of ganglion cells could be mimicked by simple changes in stimulus or lighting conditions. Figure $4 A$ shows the effect of bath-applied SS compared with that of simply extinguishing a background light, shown in Figure $4 B$, on the spiking (ratemeter record) pattern of an On ganglion cell. In both cases, the initial effect was a suppression of spontaneous activity followed by an increase in light responses. In both examples, the On (center) responses to the spot and the On (center) component of the annulus responses increased, while the Off (surround) responses did not. This suggests that the apparently coordinated actions of SS on ganglion cell receptive field properties may result from 
modulation or activation of existing retinal circuitry. Thus, when a reliable SS antagonist is available, one fruitful area of examination for a physiological role of SS, might be directed at the retinal circuitry changes associated with light and dark adaptation.

\section{Somatostatin-28}

The predominant form of SS in the rabbit retina is chromatographically identical (Sagar et al., 1982; Marshak and Yamada, 1984 ) to the 14 amino acid peptide somatostatin (usually referred to as somatostatin, as here). The 28 amino acid form of the peptide contains the 14 amino acid somatostatin sequence in its C-terminal end: SS-28 is a minor $(<10 \%)$ constituent in the rabbit retina. However, SS-28 had qualitatively and quantitatively similar effects to SS-14 in the rabbit retina $(n=10)$.

\section{Cysteamine}

A direct and obvious approach for determining the physiological role of endogenous retinal SS would be to examine the effects of SS antagonists on cells' light responses. Unfortunately, no potent, specific SS antagonist is available. Furthermore, since the effects of SS long outlast its presence at the receptors, it might be difficult to conduct and interpret antagonist experiments. We used an indirect approach for examining the role of endogenous SS by employing the agent cysteamine. This drug rapidly depletes SS in the CNS and periphery with no apparent effects on other transmitters or peptides (e.g., Sagar and Martin, 1982). Cystcaminc also deplctcs SS in the rabbit retina (Sagar and Martin, 1982). Because of the variability among retinas in SS sensitivity, comparisons of the same cell's light responses and SS sensitivity were made before and after cysteamine treatment (200-500 $\mu \mathrm{M}, 45-90 \mathrm{~min})$. We specifically looked for changes in center-surround balance after cysteamine treatment, possibly reflecting a tonic SS influence in regulating centersurround balance. However, in only 2 of 14 cells did we detect small changes in center-surround balance after cysteamine treatment. Given the length of these experiments, these small changes may not be significant. However, while center-surround changes were minimal after cysteamine, we observed dramatic changes in the sensitivity to exogenous SS, when comparing pre- and postcysteamine application. SS at $10 \mathrm{~nm}$ strongly excited 2 of 4 cells after cysteamine but 0 of 17 without such treatment. The shifts in center-surround balance produced by a given concentration of SS were clearly greater after cysteamine treatment in 4 of 5 cells; as a control, we noted that a second application of SS, to any single cell, never produced a greater center-surround effect without intervening cysteamine treatment. Thus, while we cannot argue that center-surround "tone" or balance is modulated by SS (only 2 of 14 cells showed center-surround shifts), the alterations in SS sensitivity are consistent with an ongoing "dark-release" of SS which plays a role in ganglion cell excitability.

\section{SS actions on the ERG}

Somatostatin increased the amplitude of the ERG (a-, b-, and $c$-waves) in most healthy rabbit retinas. All ERG components were augmented to about the same degree, in some cases as much as $300 \%$, as illustrated in Figure 5 . The minimum concentration which produced an obvious ERG change was less than $100 \mathrm{~nm}$. The latency of this effect after the introduction of SS was long; no changes were apparent for tens of seconds, and

\section{BEFORE

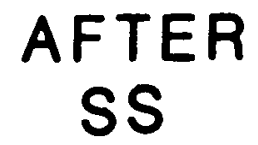

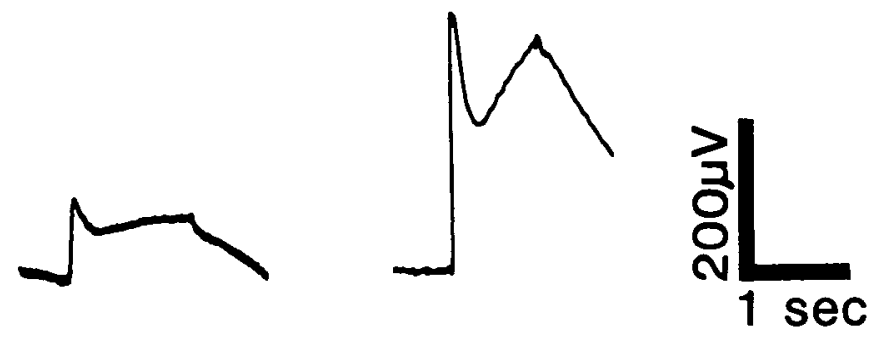

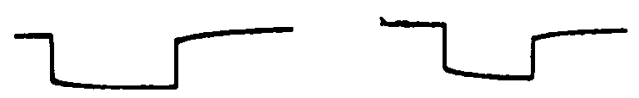

Figure 5. Somatostatin increased the amplitude of the a-, b-, and cwaves of the ERG. These records are transrctinal ERGs before and 3 min after a $30 \mathrm{sec}$ application of $250 \mathrm{~nm} \mathrm{SS}$.

the peak enhancement usually occurred a few minutes after the application began, that is, long after a $(10-60 \mathrm{sec})$ SS application had been terminated. The ERG enhancement usually persisted for tens of minutes and in many cases more than an hour. It is widely believed that the ERG reflects light-evoked activity of the distal retina. However, the magnitude of the ERG is determined by the resistivity of transretinal and extraretinal shunting. The R-membrane is the principal transretinal resistance which determines the magnitude of the ERG and has long been localized to the resistance across the pigment epithelium. Thus, the R-membrane consists of 2 parallel pathways, including a pericellular resistance across the tight junctions between neighboring pigment epithelial cells and a transcellular resistance across the proximal and distal membranes of pigment epithelial cells. A plausible explanation for the SS ERG enhancement observed in this study is an increase in R-membrane resistance, but this possibility was not tested. Until the appropriate experiments are carried out, however, we cannot eliminate the possibility that the enhancement of the ERG reflects an action of SS on the retinal network in the outer retina.

When relatively high SS concentrations (200 nM and above) were applied, more than $80 \%$ of healthy retinas showed an enhancement of the ERG, such as that illustrated in Figure 5. The observed effects of SS on the ERG, as on single cells, were clearly more variable than the changes observed with conventional transmitters in this preparation. The reported variability in SS content among rabbit retinas is also considerable, as determined by HPLC and RIA (Sagar et al., 1982). The variability that we observed in SS studies is undoubtedly an important observation and suggests that one or more variables not controlled in our experiments determines the amount of SS in the retina and the retinal sensitivity to $\mathrm{SS}$.

\section{Sites and mechanisms of SS action}

Ganglion cells. Somatostatin had direct effects upon at least some ganglion cells in the rabbit retina. Figure $6 \mathrm{~A}$ shows a SSevoked excitation of a ganglion cell in the presence of sufficient cobalt (4 mM) to block synaptic transmission. Such direct ex- 
A.
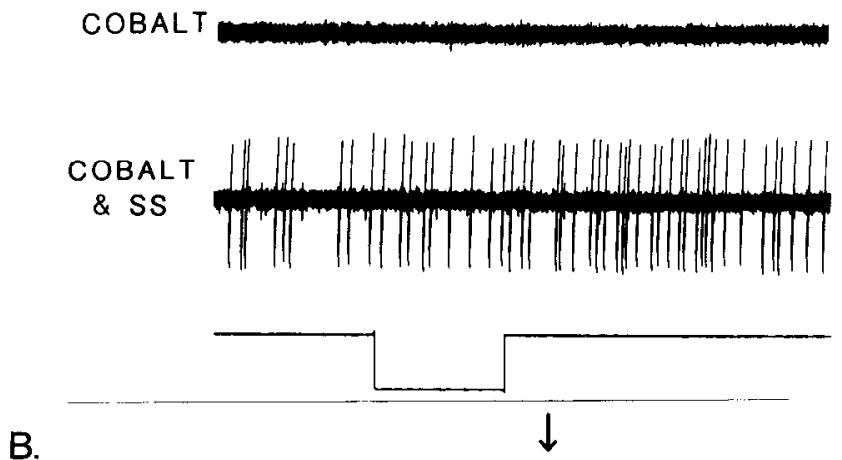

B.

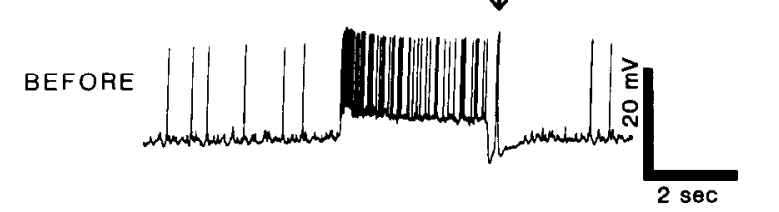

ss

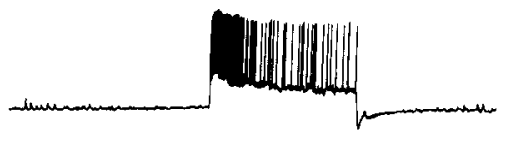

AFTER

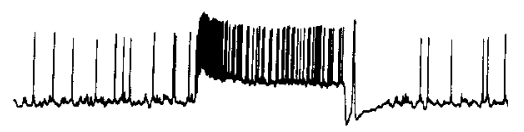

Figure 6. A, Direct excitation of a ganglion cell (extracellular recording) during complete block of synaptic transmission with cobalt ( $4 \mathrm{mM})$. The absence of response to the light stimulus (square-wave deflection) even while the cell is excited confirms the efficacy of the synaptic block. $B$, Whole-cell recording from an On ganglion cell showing the effects of SS (200 nM). The light stimulus was a large spot. The resting potential hyperpolarized by $4 \mathrm{mV}$ during SS from its original value of $-65 \mathrm{mV}$. The spontaneous activity was eliminated while the On (center) spiking increased and the Off (surround) excitation at the arrow was eliminated. The spike amplitude was markedly attenuated by the recording conditions.

citatory effects were seen in 4 of 11 ganglion cells. Since cobalt strongly reduces the excitability of ganglion cells (as determined with excitatory amino acid or cholinergic analogues on the same cells), it is quite possible that all ganglion cells are, in fact, directly affected by SS, but the effects are not always sufficient to provoke spiking during cobalt. Since the membrane potential and conductance changes produced by SS in ganglion cells are often quite small (see below), it was not possible to resolve whether all ganglion cells were directly sensitive to SS based on observations with intracellular recording.

Intracellular and whole-cell recordings from ganglion cells ( $n$ $=18$ ) showed changes in receptive field properties similar to those seen in extracellular recordings. Figure $6 B$, for example, is a wholc-cell recording from an On ganglion cell responding to a large spot stimulus. The spontaneous activity was eliminated by SS while the On (center) spiking clearly increased, i.e., the "signal-to-noise" increased. The Off excitation (at arrow), contributed by the surround with this large spot stimulus, was eliminated during the SS effect, indicating a shift in centersurround balance. These spiking changes were accompanied by

a small hypcrpolarization ( $4 \mathrm{mV}) ; 0-5 \mathrm{mV}$ hyperpolarizations were seen in other ganglion cells in response to SS. The hyperpolarizations associated with SS application suggest that a conventional conductance increase (excitatory) mechanism is unlikely to account for the action of SS at the ganglion cell level.

Bipolar and amacrine cells. We carried out intracellular and whole-cell recordings from 30 inner retinal neurons which were judged to be nonganglion cells, based on previous analyses in this and other laboratories (Bloomfield, 1981; Bloomfield and Miller, 1982; Dacheux and Raviola, 1982, 1986). Virtually all of these neurons ( 28 of 30 ) showed an increase in light-response amplitude when SS was applied. In most cases, hyperpolarizations accompanied these changes. Figure $7 A$ shows a presumed On-Off amacrine cell and illustrates the hyperpolarization and light-response increase evoked by SS. The depolarizing cell in Figure $7 B$, which showed a slight hyperpolarization and pronounced light-response increase when SS was applied, is likely to be a depolarizing bipolar since, in general, these cells are considerably less noisy than sustained amacrine cell types, such as the A-II and A17 amacrine cells.

The increase in light responses seen with intracellular recordings was not secondary to the hyperpolarization since response enhancements persisted in cells when their original dark membrane potentials were restored using extrinsic current, as illustrated in Figure $7 C$.

Many cells showed an obvious increase in membrane noise level during the SS effects, as seen in Figure $7 C$. The $5-10 \mathrm{mV}$ of noise often present in amacrine cells can be substantially reduced (to $<1 \mathrm{mV}$ ) by cobalt $(4 \mathrm{~mm}$ ) block of synaptic transmission, and, so, is probably of synaptic origin. The increase in noise during SS suggests either an increase in synaptic input or an increase in the input resistance of the cell.

It is technically difficult to measure input conductance changes in mammalian inner retinal neurons because of the intrinsic properties of the cells and the difficulties of working with the very fine micropipettes necessary to impale them. Nevertheless, changes in input resistance were detected following SS in 5 cells in which the electrode characteristics were clearly stable during the course of the experiments. In all 5, an increase in input resistance was associated with SS application and clearly timelocked to the changes in light response. An increase in resistance is consistent with the increases in synaptic noise detected in the majority of inner retinal neurons, as described above. In Figure $8 A$, the voltage deflections produced by intracellular current pulses were approximately cancelled with the bridge circuit of the amplifier. The increased voltage deflections to the same current pulses after SS suggest an increase in input resistance. The SS-induced conductance changes were usually less than $10 \%$ of the measured input resistance of the cell (shunting around the electrode would tend to reduce the measured changes, so the real changes may be a larger percentage of the input resistance). That a hyperpolarization often accompanies the decrease in conductance following SS application implies that the net equilibrium potential for the affected conductances is more positive than the dark potential. Current-voltage relationships derived from current-clamp measurements (Fig. $8 B$ ) confirmed this. Thus, our observations suggest that SS action on inner retinal neurons is probably due, in part, to the closing of ionic channels whose reversal potential is relatively positive, suggesting that cation channels $\left(\mathrm{Na}^{+}\right.$and $\mathrm{K}^{+}$, or possibly $\left.\mathrm{Ca}^{2+}\right)$ may be involved. Whether these measured changes reflect modulations of direct or indirect actions of SS remains to be established. 

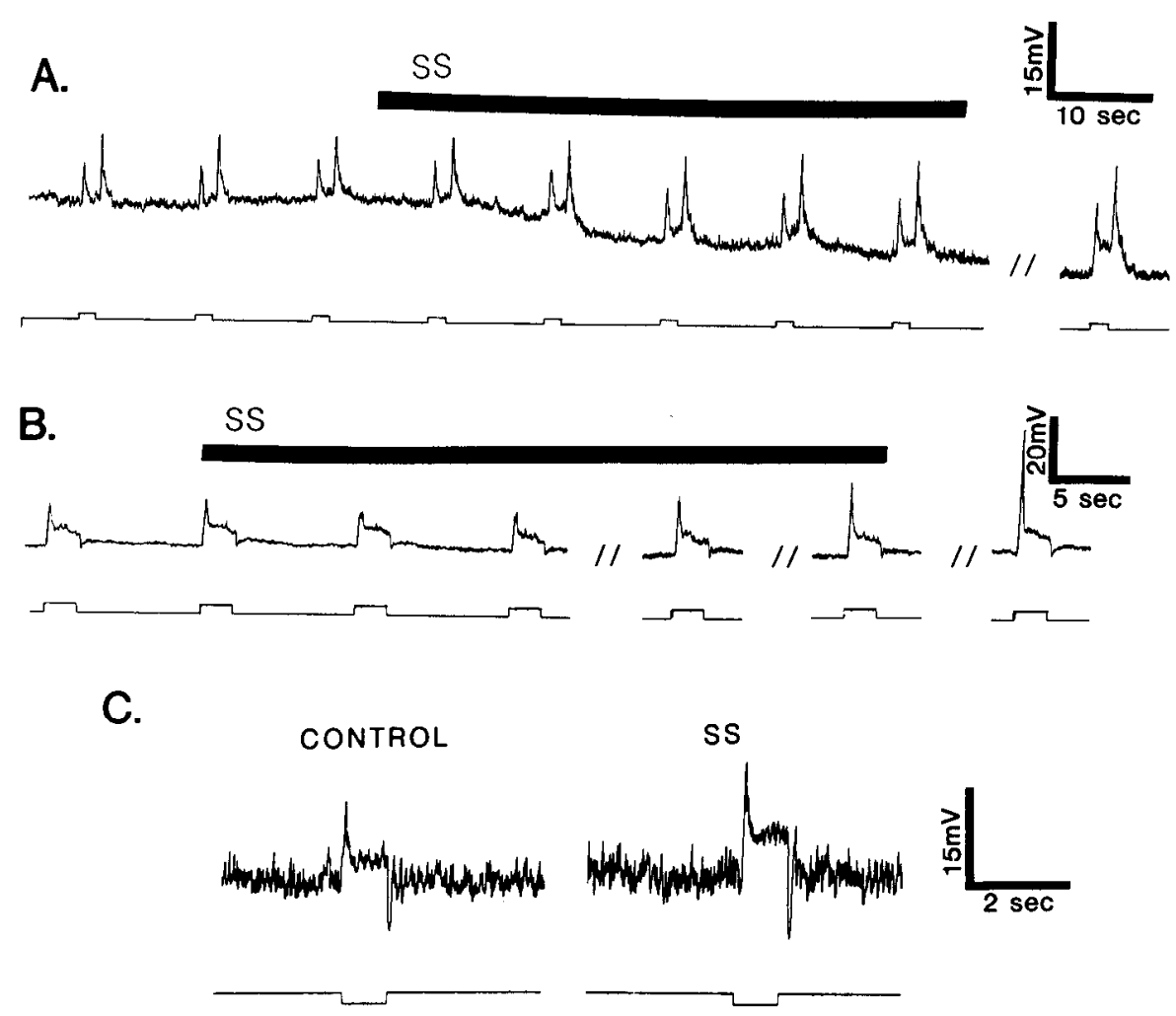

Figure 7. Intracellular records from inner retinal neurons which show the slow hyperpolarization and enhancement of the light responses following $S S$ application. The cell in $A$ was a probable On-Off amacrine cell, and the cell in $B$ a bipolar cell based on published intracellular staining studies in the rabbit retina. In $C$, the light response and synaptic noise of a sustained On amacrine (possible A-II or A17) were increased following SS despite the lack of a significant hyperpolarization, suggesting a conductance decrease mechanism for SS action.

Horizontal cells. Horizontal cells probably contribute substantially to the spatial surrounds of ganglion cells. Because SS can strongly reduce the surround influence at the ganglion cell level, it was surprising that SS had no apparent effects on the resting potentials, light responses, input impedances, and receptive field areas of intracellularly recorded horizontal cells ( $n$ $=40$ ). Figure $9 A$, for example, shows the lack of effect of a high dose $(1 \mu \mathrm{M})$ of SS on the small and large spot responses of a horizontal cell. Figure $9 B$ shows the absence of effect of $1 \mu \mathrm{M}$ SS on the responses of another horizontal cell to a $4 \log$ unit range of light intensitics.

Thus, a function (surround) commonly attributed to horizontal cells is reduced at the ganglion cell level by SS, but without apparent physiological changes in the horizontal cells themselves. In order to resolve this paradox, we determined whether SS altered the pathway for horizontal cell influences on ganglion cells. For these experiments, we carried out dual, simultaneous recordings from a horizontal cell (intracellular) and a nearby ganglion cell (extracellular) to evaluate the physiological connectivity between the pair and to determine whether SS affected this connection. This approach clearly demonstrated that the horizontal cell influence on the ganglion cell was sharply reduced by $\mathbf{S S}$.

The dual recording paradigm is illustrated in Figure $10 \mathrm{~A}$. The top row shows intracellular records from a horizontal cell responding to a small spot and an annulus. The spot and annulus are indicated by upward and downward deflections, respectively, shown in the third trace. The second row shows ratemeter records from a simultaneously recorded (extracellular) On center ganglion cell responding to the same stimuli. The receptive field centers of the 2 cells were within $200 \mu \mathrm{M}$, as determined by a moveable $100 \mu \mathrm{M}$ slit stimulus. The horizontal cell light responses were unchanged after SS (100 nM). The ganglion cell records after SS show the characteristic elimination of spontaneous activity, increase in the On (center) responses to both light stimuli, and a decrease in the Off (surround) excitation from the annulus. The bottom row of Figure 10 shows the results when current ramps were injected through the intracellular electrode into the horizontal cell. The ratemeter records of the ganglion cell's response to this procedure are shown just above the current traces. Clearly, before SS application, the horizontal cell current injections modulated the ganglion cell firing, but this influence was completely lost after the introduction of SS.

A decrease in apparent horizontal cell influence logically might arise from a simple inhibition or diminished excitability at the ganglion cell itself. The decreased spontaneous activity suggests this, but the increased center responses argue strongly against this possibility. Figure $10 \mathrm{~B}$ presents further evidence against such a simple interpretation. The experimental paradigm for this experiment was the same as that of the previous figure, except that the ganglion cell is an Off center cell and the light stimuli are a small spot (upward deflection) and a diffuse light (downward deflection). Again, the horizontal cell light responses were unchanged after SS (top traces). SS did not reduce the spontaneous activity of this ganglion cell but did increase the Off (center) responses to the spot and particularly to the diffuse light (as expected from a reduction in surround inhibition). The ratemeter records of the ganglion cell's responses to the injection of current ramps (bottom traces) to the horizontal cell are presented in the third row of the figurc. Clcarly, SS diminished the horizontal cell to ganglion cell influence, even though the ganglion cell's spontaneous activity and excitability had not diminished. Thus, in this example, we clearly observe that the loss of horizontal cell influence is not simply due to an inhibition at the ganglion cell level.

Eighteen dual recording experiments between horizontal and 
A.

\section{CONTROL}

\section{SS}
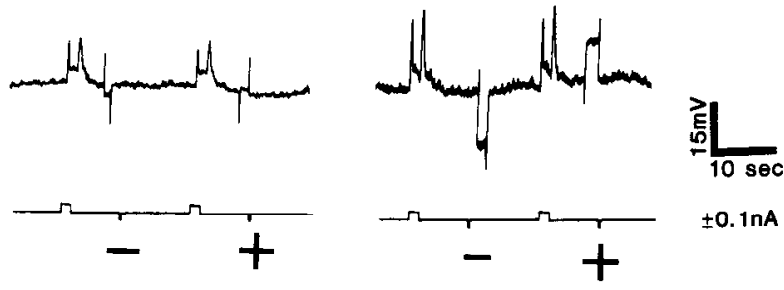

B.
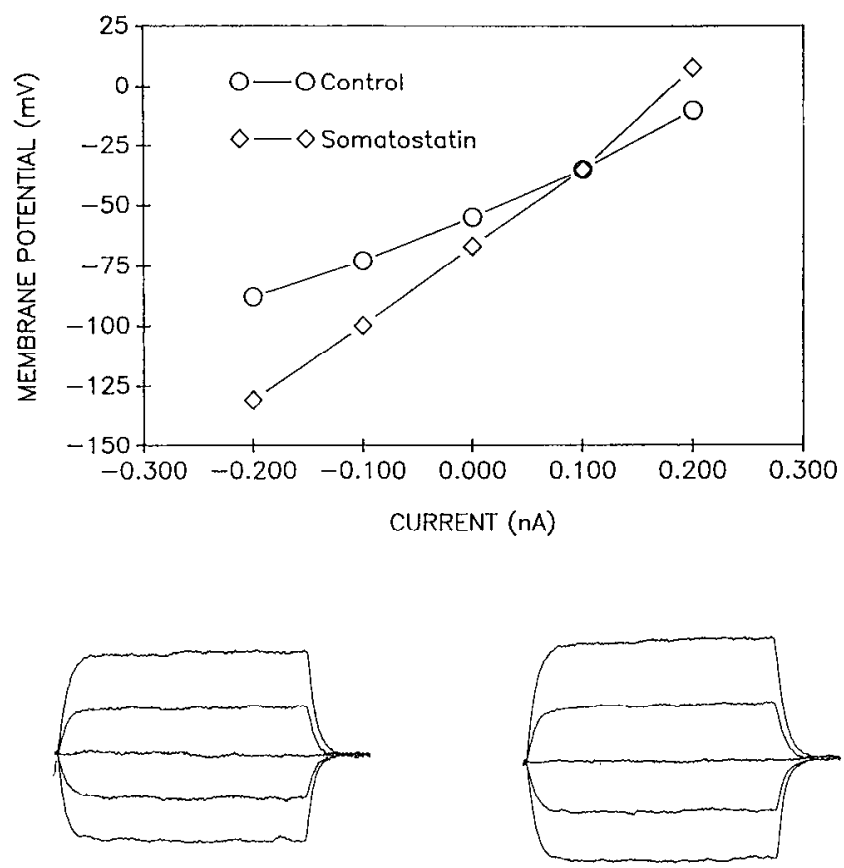

CONTROL

SOMATOSTATIN

Figure 8. A, An intracellular recording from an On-Off amacrine cell illustrates an increase in input resistance following SS application. The bridge circuit was adjusted to approximately cancel the voltage deflection produced by the current pulses before SS (upper trace, left). The increased voltage deflections to the same current pulses after SS (upper trace, right) indicate an increase in input resistance. $B$, Current-voltage relationship of the On-Off amacrine cell before and during SS application. The input resistance is clearly increased following SS, and the reversal potential is more positive than the cell's resting potential. Bottom traces show the voltage deflections used to construct the plot in $B$.

ganglion cells were carried out. Several controls were established to validate our conclusions about these experiments. First, current injected through the intracellular electrode before or after recording from a horizontal cell (with the electrode tip in the extracellular space) had no effect on ganglion cell excitability. Second, the polarity of current necessary to modulate the ganglion cell was opposite for On vs Off ganglion cells and was consistent with that expected if the horizontal cells contribute to the receptive field surrounds of ganglion cells. Most importantly, when SS had clear effects on ganglion cell surrounds, the horizontal cell influence assessed by current injection was also reduced (14 pairs), and when an application of SS did not substantially attenuate the receptive field surround, the horizontal

cell influence was also retained (4 pairs). These observations have implications about horizontal cell mechanisms and the pathway in the retinal circuitry where they exert their action.

\section{SMS 201-995}

The conformationally restricted, synthetic SS analog SMS201995 (gift of Sandoz; Tran et al., 1985) is very slowly degraded in biological systems. The effects of this analog in the rabbit retina appear qualitatively and quantitatively similar to those of SS itself ( $n=15)$. Figure 11 shows, for example, the effects of SS, SMS201-995, and glutamate on an On direction-selective cell (ratemeter records). Both SS and the SMS analog selectively increased the preferred direction response (arrows at the bottom indicate direction of stimulus movement), while glutamate ( 1 $\mathrm{mm}$ ) (or carbachol, not shown) sufficient to increase the preferred direction response brought out excitation in the null direction as well.

It is important to emphasize that the degradation-resistant analog SMS 201-995 was not more potent than SS itself in the retina. In systems where degradation limits SS actions (such as systemic injections), this widely used analog is far more potent, although its receptor affinity is not greater than SS itself. This suggests that SS may be degraded slowly enough in rabbit retina that it can diffuse and act at some distance from the site or sites of release. This is very different from our observations on substance $\mathrm{P}$ degradation in the same preparation (Zalutsky and Miller, 1990, accompanying paper), so it does not reflect abnormally slow peptide degradation in general in this in vitro preparation.

\section{Discussion}

Somatostatin is present in neurons of the rabbit retina (Sagar et al., 1982; Marshak and Yamada, 1984). The results reported here suggest that SS may be a modulator in the rabbit retina, acting at multiple levels of the retinal network to produce a long-lasting enhancement in the "signal-to-noise" ratio (i.e., the ratio of light-evoked to spontaneous activity) and shifts in center-surround balance (toward more dominant centers) of ganglion cells.

\section{Time course of SS actions}

The time course of SS effects are important for delimiting possible functions of this peptide in the retina. Even the most rapid effects, the excitations observed at higher concentrations, have latencies a few seconds longer than those of amino acid transmitters or substance P applied to the same cells. Since SS directly excites ganglion cells, this latency difference is unlikely duc to differences in diffusion time. Clearly, SS acts too slowly to participate in any fast, light-activated responses.

The signal-to-noise and center-surround changes have much longer latencies (several seconds) and sometimes persist more than an hour after SS has been washed from the system. It is not apparent what function such long-lasting actions might have, but slow onset changes in these parameters might represent a post-photoreceptor component of adaptation (cf. Rushton, 1965; Dowling and Ripps, 1977). Similar receptive field changes lasting perhaps tens of minutes do occur with changes in lighting conditions (Barlow et al., 1957). It is important to note that the less dramatic the changes induced by a particular application of SS, the more briefly they persisted; some clear signal-to-noise and center-surround changes reversed within about 10 minutes. Even 10-20 sec bath applications of the peptide, the briefest 
A. SS

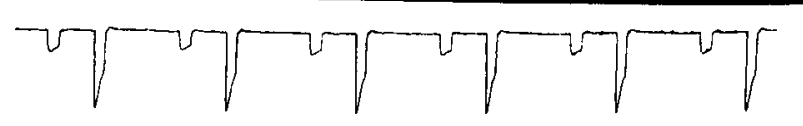

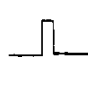

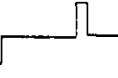

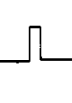

4

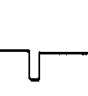

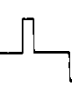

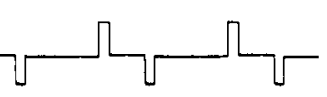

$2 \min$
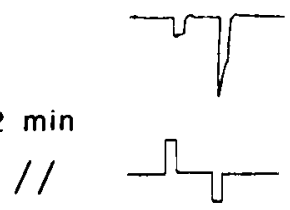

B.

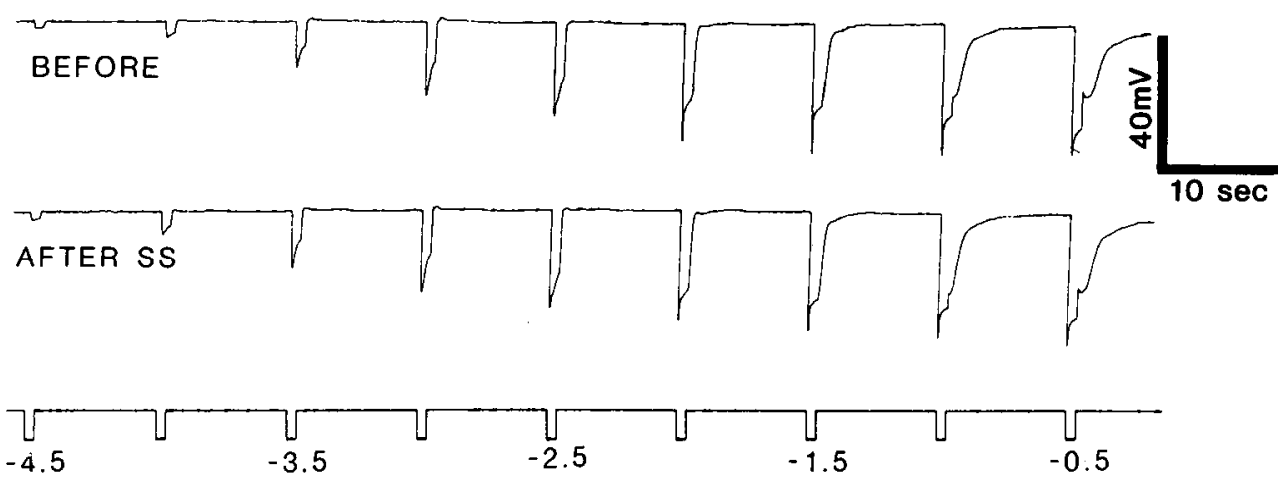

Figure 9. Intracellular recordings from horizontal cells demonstrate the apparent lack of effects of even high concentrations of SS on the membrane potential or light-evoked response of these cells. $A$, Small and large spot responses. $B$, A $4 \log$ unit range of light intensities (full field) before and after SS $(1 \mu \mathrm{M})$ application.

used here, may be unphysiologically long and result in longerduration effects than naturally occur. Another possibility is that some active mechanism may normally reset the changes produced by SS.

\section{Mechanisms of SS actions}

The cellular mechanism of SS action is very difficult to determine in an intact mammalian retina, so our observations on this issue should be taken cautiously. It appears that at least one of the actions of SS is to decrease the conductance of an ion channel whose net equilibrium potential is more positive than that of the dark membrane potential. This action could contribute to the "signal-to-noise" changes. Such a conductance change would hyperpolarize a cell, moving the membrane potential away from spike threshold, thereby reducing spontaneous spiking. Since the input resistance of these cells would be increased after SS, any excitatory input mediated by a conductance increase would have a greater effect on the voltage of the cell. This simple hypothesis begins to break down, however, if the spontaneous activity of the cell is also the result of a low-level release in the dark of some excitatory drive. Thus, the greater center response observed with SS application probably depends, in part, on greater synaptic drive from the center pathway. We clearly observed enhanced responses in other retinal neurons, some of which were undoubtedly bipolar cell recordings.

SS acts on neurons by a number of different cellular mechanisms (Delfs and Dichter, 1985), including modulation of voltage-dependent conductances, an effect which would be difficult to resolve with the present methods (Jacquin et al., 1988; Moore et al., 1988). Furthermore, peptides often affect multiple conductances, even on the same cells (e.g., Barker et al., 1978; Dun and Minota, 1981; Murase et al., 1986). Some of the results in the rabbit retina (e.g., the horizontal cell influence on ganglion cells discussed below) raise the possibility that SS may act presynaptically on conductances regulating transmitter release.
Further experiments-and probably different methods - will be required to resolve the full spectrum of cellular actions by which SS acts in the rabbit retina.

\section{Sites of SS action}

Intracellular and extracellular recordings during cobalt block of synaptic transmission demonstrate that SS can affect ganglion cells and other inner retinal neurons. These experiments argue for a direct action of SS on third-order cells. The dual-electrode experiments suggest that SS decreases the influence of horizontal cells upon ganglion cells, and this obviously could contribute significantly to the center-surround changes observed in ganglion cell recordings. Our experimental findings strongly suggest that this action of SS cannot be due to its direct effects on ganglion cells but must reside elsewhere in the retinal circuitry. Where in the circuitry this action takes place is not at all clear. Although immunochemical staining has so far revealed SS-containing cells to be in the inner retina, kainate lesions of the inner retina eliminate only about half of the retinal SS content (Sagar et al., 1983). In this regard, experiments with the nondegraded SS analog SMS 201-995 in the present study suggest that SS may be degraded slowly enough in the rabbit retina to diffuse and act a considerable distance from its release sites.

The only known action of horizontal cells is through a feedback influence onto cones, as first established in the turtle retina. Although direct proof is lacking, it has been taken as an article of faith that horizontal cells work similarly in mammals. The action of a feedback synapse onto cone terminals implies that the horizontal cell can modulate the voltage response of the photoreceptor and, in turn, influence its own voltage response. Thus, if SS acted at the feedback synapse to suppress horizontal cell influence on cone terminals, we would expect to see the effects of this altered cone response on the horizontal cell itself. Our observations are clearly inconsistent with this interpretation of SS action, since horizontal cell light responses (and dark 
A.

A. BEFORE

HORIZONTAL CELL 2T Tr

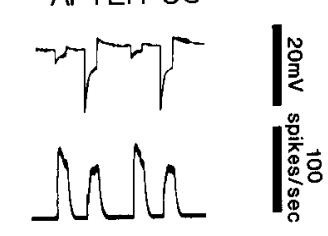

CELL

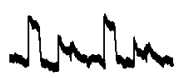

LIGHTS

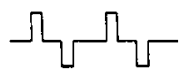

(ratemeter)

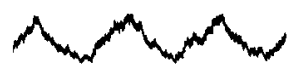

CURRENT $\wedge \vee$

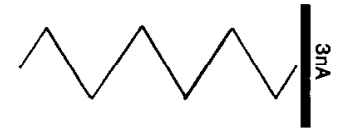

B.

B. BEFORE
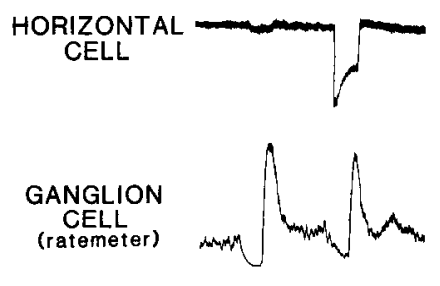

LIGHTS
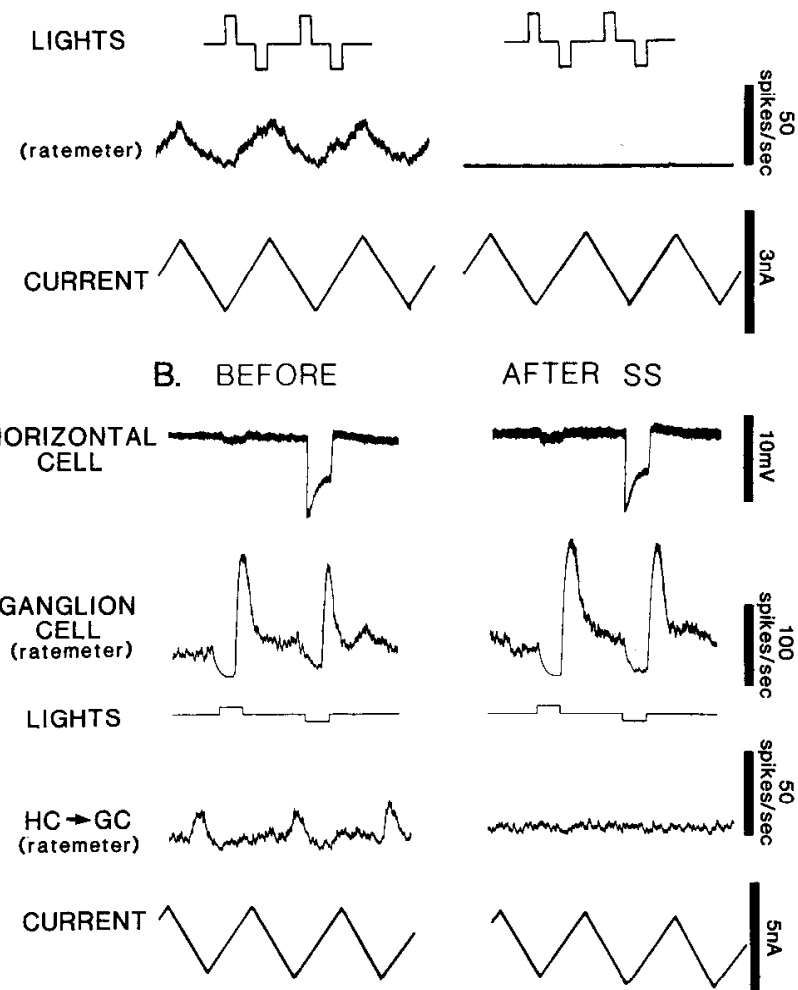

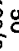

\section{ON DIRECTION SELECTIVE CELL (ratemeter)}

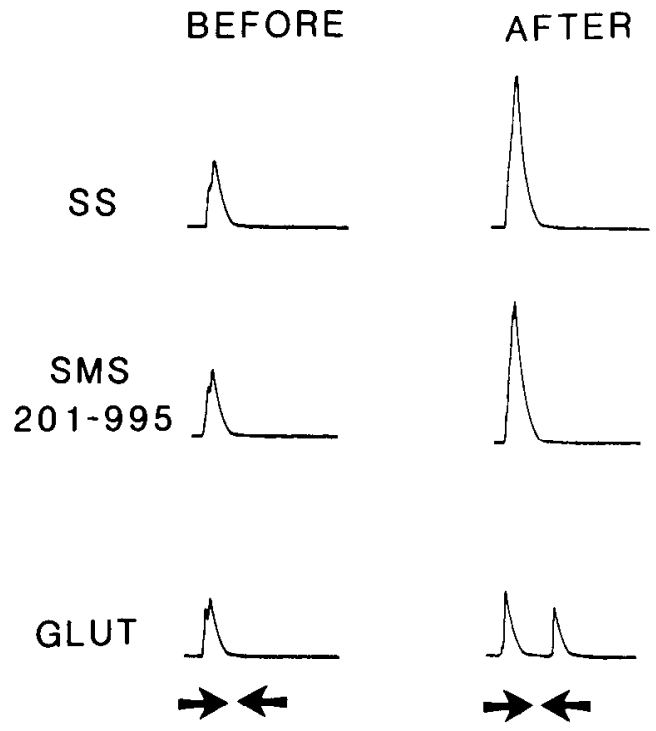

Figure 11. SS and the analog SMS 201-995 both selectively increased the preferred direction response of this On direction-selective cell. Concentrations of glutamate sufficient to have an effect on the preferred direction response also excited for movement in the null direction. The arrows indicate the direction of movement of a $100 \mu \mathrm{M}$ slit moving at $1 \% \mathrm{sec}$. Concentrations of SS and SMS 201-995 were $200 \mathrm{nM}$ and of glutamate, 1 mм.

membrane potential) were unaffected by SS application, even when very high doses of this peptide were applied. Despite this lack of SS action of the horizontal cell light responses, we clcarly showed a powerful effect of SS in eliminating the ability of horizontal cells to drive the retinal network using dual horizontal and ganglion cell recordings. The loss of this physiological connectivity is clearly consistent with the decrease in the receptive field surround observed at the level of the ganglion cells. Clearly, we cannot account for the loss of the surround and the lack of effect on horizontal cells by placing the action of SS on the feedback synapse to the cone terminals. An alternative possibility, of course, is that some or all of the influence of horizontal cells in the rabbit is mediated by feedforward connections. An older, often neglected, ultrastructural analysis (Dowling et al., 1966) suggested that feedforward synapses from horizontal cells to bipolar cells were present in the rabbit and cat retinas. If this were the site of SS action, we could expect to see loss of the surround mediated by horizontal cells with preservation of the horizontal cell light response.

One additional possibility is that part of the surround is not mediated by horizontal cells but rather from inner retinal connectivity. In this regard, the surround excitation, which is selectively blocked by SS (Fig. 6), has never been observed in our population of intracellular recordings from bipolar cells, suggesting that inner retinal mechanisms might also be contributing cells is not simply the result of decreased excitability of the ganglion cell itself. The experimental paradigm is the same as that in $A$. The top row shows intracellular records of a horizontal cell in response to a small spot (upward deflection) and a full-field stimulus (downward deflection). Below are ratemeter records of a simultaneously recorded Off ganglion cell to the same light stimuli. The bottom ratemeter records show the response of the ganglion cell to a ramp of current injected into the horizontal cell. Note that in this case, downward, or negative current injections are associated with increased firing in the ganglion cell, just the opposite relationship to the On cell in $A$. At right, it is apparent that

\section{$\leftarrow$}

the ganglion cell did not experience a decrease in spontaneous firing usually seen with SS, but the cell could no longer be modulated by current injections into the horizontal cell. Thus, interruption of the horizontal cell pathway to the ganglion cell is not based on a decrease in excitability at the ganglion cell itself. 
to this receptive field property. We submit that the details of horizontal cell mechanisms and inner retinal physiology in the rabbit retina are not sufficiently clear to engage in anything other than speculation about how to reconcile the paradoxical actions of SS on the receptive field surround with its lack of direct action on horizontal cells.

\section{Possible functions of SS}

Because SS is present in the rabbit retina and bath-applied SS alters ganglion cell light responses does not necessarily imply a functional role for endogenous retinal SS. The increased sensitivity to applied SS in retinas which have been depleted of the peptide (by cysteamine) does, however, suggest some functional role for retinal SS. That is, if depleting a retina of SS raises the sensitivity to exogenous SS, endogenous SS is likely to be activating SS receptors under the conditions of our experiments. This also implies that SS is continuously (dark) released and that our observations on SS action represent stimulation of the unoccupied receptors. Perhaps a more compelling argument derives from the very low concentrations at which applied SS can act (i.e., $<1 \mathrm{nM}$ ). If enough $\mathrm{SS}$ is released from endogenous pools to activate known SS receptors (Reichlin, 1983), those concentrations would be sufficient to produce the signal-to-noise and center-surround effects described here.

If endogenous SS is a "first messenger" in the rabbit retina, it clearly must be a slow modulator rather than a fast transmitter. Even the most rapid effects are too slow to contribute to shaping the defining receptive field properties of ganglion cells. The center-surround and signal-to-noise effects suggest a role in adaptation or long-term adjustment of retinal circuitry, but a better understanding of the conditions under which SS is released will be required before we can attribute a functional role for this peptide in the rabbit retina.

\section{References}

Ames, A., and F. B. Nesbett (1981) In vitro retina as a experimental model of the central nervous system. J. Neurochem. 37: 867-877.

Barker, J. L., J. H. Neale, and T. G. Smith (1978) Multiple mechanisms of enkephalin revealed using cultured spinal neurons. Brain Res. 154: 153-158.

Barlow, H. B., R. Fitzhugh, and S. W. Kuffler (1957) Change of organization in the receptive fields of the cats retina during dark adaptation. J. Physiol. (Lond.) 137: 1639-1641.

Bloomfield, S. A. (1981) A physiological-morphological study of neuronal pathways in the rabbit retina. Ph.D. Dissertation, Washington University, St. Louis, MO.

Bloomfield, S. A., and R. F. Miller (1982) A physiological and morphological study of the horizontal cell types of the rabbit retina. $J$. Comp. Neurol. 208: 288-303.

Caldwell, J. H., and N. W. Daw (1978) New properties of rabbit retinal ganglion cells. J. Physiol. (Lond.) 276: 257-276.

Coleman, P. A., and R. F. Miller (1986) Whole cell recording from cells of the intact vertebrate retina. Invest. Ophthalmol. Vis. Sci. Suppl. 27: 283.

Dacheux, R. F., and E. Raviola (1982) Horizontal cells in the retina of the rabbit. J. Neurosci. 2: 1486-1493.

Dacheux, R. F., and E. Raviola (1986) The rod pathway in the rabbit retina: A depolarizing bipolar and amacrine cell. J. Neurosci. 6: 331345 .

Delfs, J. R., and M. A. Dichter (1985) Somatostatin. In Neurotransmitter Actions in the Vertebrate Nervous System, M. A. Rogawski and J. L. Barker, eds., pp. 411-432, Plenum, New York.
Dowling, J. E., and H. Ripps (1977) The proximal negative response and visual adaptation in the skate retina. J. Gen. Physiol. 69: 57-74.

Dowling, J. E., J. E. Brown, and D. Major (1966) Synapses of horizontal cells in rabbit and cat retinas. Scicnce 153: 1639-1691.

Dun, N. J., and S. Minota (1981) Effects of substance P on neurones of the inferior mesenteric ganglia of the guinea pig. J. Physiol. (Lond.) 321: 259-271.

Epelbaum, J. (1986) Somatostatin in the CNS: Physiology and pathological modifications. Prog. Neurobiol. 27: 63-100.

Grimm-Jørgenson, Y. (1987) Somatostatin and calcitonin stimulate neurite regeneration of molluscan neurons in vitro. Brain Res. 403. 121-126.

Jacquin, T., J. Champagnat, M. Devavit-Saubie, and G. R. Siggins (1988) Somatostatin depresses excitability in neurons of the solitary tract complex through hyperpolarization and augmentation of Im, and non-inactivating voltage-dependent outward current blocked by muscarinic agonists. Proc. Natl. Acad. Sci. USA 85: 948-952.

Lcvick, W. R. (1972) Another tungsten microclectrode. Med. Biol. Engin. 10: 510-515.

Marshak, D., and T. Yamada (1984) Characterization of somatostatinlike immunoreactivity in vertebrate retinas. Invest. Ophthalmol. Vis. Sci. 25: 112-115.

Miller, R. F., R. A. Zalutsky, and S. C. Massey (1986) A perfused rabbit retina preparation suitable for pharmacological studies. J. Neurosci. Methods 16: 309-322.

Moore, S. D., S. G. Madamba, M. Joels, and G. R. Siggins (1988) Somatostatin augments the M-current in hippocampal neurons. Science 239: 278-280.

Murase, K., P. D. Ryu, and M. Randic (1986) Substance P augments a persistent calcium sensitive current in voltage clamped spinal dorsal horn neurons of the rat. Brain Res. 365: 369-376.

Reichlin, S. (1983) Somatostatin, in Brain Peptides, Wiley, New York.

Robbins, R. J. (1983) The influence of glucose on somatostatin synthesis and secretion in isolated cerebral cortical cells. J. Neurochem. 40: 1430-1434.

Rushton, W. A. H. (1965) Visual adaptation. Proc. R. Soc. London [Biol.] 162: 301-304.

Sagar, S. M. (1987) Vasoactive intestinal polypeptide (VIP) immunohistochemistry in the rabbit retina. Brain Res. 426: 157-163.

Sagar, S. M., and J. B. Martin (1982) The effect of cysteamine on immunoreactive somatostatin in the rabbit retina. Neurosci. Lett. 34 : 265-269.

Sagar, S. M., O. P. Rorstad, D. M. D. Landis, M. A. Arnold, and J. B. Martin (1982) Somatostatin-like immunoreactive material in the rabbit retina. Brain Res. 244: 91-99.

Sagar, S. M., L. Weinstein, J. F. Reinhard, Jr., and J. B. Martin (1983) A comparison of the effects of kainic acid on somatostatin, substance $\mathrm{P}$ and dopamine in the rabbit retina. Brain Res. 278: 109-115.

Sagar, S. M., P. E. Marshall, S. T. Onesti, and D. M. D. Landis (1986) Somatostatin immunocytochemistry in the rabbit retina. Invest. Ophthalmol. Vis. Sci. 27: 316-322.

Tran, V. T., M. F. Beal, and J. B. Martin (1985) Two types of somatostatin receptors differentiated by cyclic somatostatin analogues. Science 228: 492-495.

Vaney, D. I., W. R. Levick, L. N. Thibos (1981) Rabbit retinal ganglion cells. Exp. Brain Res. 44: 27-33.

VanItallic, C., and J. D. Fernstrom (1982) Hypothalamic somatostatin biosynthesis: Effects of anesthetics and hypophysectomy. Brain Res. 249: 177-183.

Zalutsky, R. A., and R. F. Miller (1985) Physiological actions of ncuropeptides on rabbit retinal cells. Invest. Ophthalmol. Vis. Sci. Suppl. 26: 117 .

Zalutsky, R. A., and R. F. Miller (1986) Neurotensin actions in the retina: Mechanism and variability. Brain Res. 371: 360-363.

Zalutsky, R. A., and R. F. Miller (1987) The physiology of somatostatin in the rabbit retina. Soc. Neurosci. Abstr. 13: 381.

Zalutsky, R. A., and R. F. Miller (1990) The physiology of substance $P$ in the rabbit retina. I. Neurosci. 10: 394-402. 